\title{
Liver Sinusoidal Endothelial Cells Are Responsible for Nitric Oxide Modulation of Resistance in the Hepatic Sinusoids
}

\author{
Vijay Shah, ${ }^{* \mid \pi}$ Fadi G. Haddad, ${ }^{\neq \llbracket ~ G u i l l e r m o ~ G a r c i a-C a r d e n a, ~}{ }^{\S}$ John A. Frangos, ${ }^{\star *}$ Albert Mennone, Roberto J. Groszmann, ${ }^{* \mid \pi}$ \\ and William C. Sessa $\$$ \\ *Department of Medicine, ${ }^{\ddagger}$ Department of Pediatrics, ${ }^{\S}$ Department of Pharmacology, and ${ }^{\|}$Yale Liver Center, Yale University School of \\ Medicine, New Haven, Connecticut 06520; "Hepatic Hemodynamic Laboratory, West Haven VA, West Haven, Connecticut 06536; and \\ **Department of Bioengineering, University of California, San Diego, La Jolla, California 92093
}

\begin{abstract}
The mechanisms that regulate vascular resistance in the liver are an area of active investigation. Previously, we have shown that nitric oxide (NO) modulates hepatic vascular tone in the normal rat liver. In this study, the production of NO is examined in further detail by isolating sinusoidal endothelial cells (SEC) from the rat liver. Endothelial NO synthase (eNOS) was present in SEC based on Western blotting and confocal immunofluorescence microscopy. Exposure of SEC to flow increased the release of NO. To investigate the relevance of these in vitro findings to the intact liver, we modified an in situ perfusion system to allow for direct measurement of NO release from the hepatic vasculature. NO was released from the hepatic vasculature in a time-dependent manner, and administration of $\mathrm{N}$-monomethyl-L-arginine reduced NO release and increased portal pressure. Immunostaining of intact liver demonstrated eNOS localization to endothelial cells lining the hepatic sinusoids. These findings demonstrate that SEC in vitro and in vivo express eNOS and produce NO basally, and increase their production in response to flow. Additionally, an increase in portal pressure concomitant with the blockade of NO release directly demonstrates that endogenous endothelialderived NO modulates portal pressure. (J. Clin. Invest. 1997. 100:2923-2930.) Key words: nitric oxide • endothelial cell $\bullet$ vascular resistance $\bullet$ liver $\bullet$ blood flow
\end{abstract}

\section{Introduction}

Nitric oxide $(\mathrm{NO})^{1}$ is a vasodilatory molecule that modulates tone in several vascular beds, including the lung and systemic circulation $(1,2)$, and plays a role in other physiological pro-

Address correspondence to William C. Sessa, Ph.D., Boyer Center for Molecular Medicine, Room 436B, Yale University School of Medicine, 295 Congress Ave., New Haven, CT 06536-0812. Phone: 203-737-2291; FAX: 203-737-2290; E-mail: william.sessa@yale.edu

Received for publication 23 April 1997 and accepted in revised form 24 September 1997.

1. Abbrevations used in this paper: eNOS, endothelial NO synthase; HSC, hepatic stellate cells; iNOS, inducible NO synthase; IPRL, isolated perfused rat liver; IVC, inferior vena cava; L-NMMA, $N$-monomethyl-L-arginine; NNA, $N$-nitro-L-arginine; NO, nitric oxide; $\mathrm{NO}_{\mathrm{x}}$, the sum of $\mathrm{NO}$ breakdown products $\mathrm{NO}_{2}{ }^{-}, \mathrm{NO}_{3}{ }^{-}$, and nitrosothiols; SEC, sinusoidal endothelial cells; TEM, transmission electron microscopy.

The Journal of Clinical Investigation

Volume 100, Number 11, December 1997, 2923-2930

http://www.jci.org cesses such as angiogenesis, cell growth, and migration (3). Distinct cDNAs have been isolated for a cytokine inducible NO synthase (iNOS), expressed in macrophages, vascular smooth muscle, hepatic stellate cells (HSC), and hepatocytes, as well as two distinct but related constitutive NO synthases (4). One is synthesized in varying degrees by endothelial cells (eNOS) and the other by neuronal cells (4). Although iNOSderived NO production is regulated predominantly at the transcriptional level, eNOS-derived NO production can be regulated at multiple cellular levels. Two novel mechanisms found to regulate eNOS and NO release include the subcellular targeting of the enzyme (5-6), and biomechanical forces such as flow and the attendant shear stress (7-9). Whereas the regulation of iNOS has been examined previously in the hepatic sinusoid (10), the level of expression and subcellular localization of eNOS in hepatic sinusoidal endothelial cells (SEC) and the effects of regulatory mechanisms such as flow have not been described.

Blood flow and vascular resistance in the hepatic microvasculature are intimately regulated (11); however, the cellular and molecular mechanisms responsible for the regulation of hepatic vascular resistance are not well understood. The hepatic microcirculation is unique among vascular beds. Whereas in most organ beds, the site of blood flow regulation occurs at the arteriolar level, in the liver, $90 \%$ of blood flow enters through the portal vein, and resistance changes are thought to occur in the microvascular anastomosis of the portal vein and the hepatic vein, termed the hepatic sinusoid (12). The endothelial cells that line these vessels are anatomically and biologically distinct from their endothelial cell counterparts in other organs and vessels in important ways. These cells lack a basement membrane and contain fenestrae, characteristics that facilitate the transport of nutrients and macromolecules between the sinusoids and the hepatic parenchyma (13). Several vasoactive endothelium-derived substances have been postulated to play a role in the regulation of intrahepatic resistance, including NO (14-21). In one study, the infusion of $N$-nitro-L-arginine (NNA), an NO synthase inhibitor, increased significantly portal pressure in the normal rat liver in vivo and in vitro (14); however, another study reported dissimilar results (21). Activation of eNOS by agonists typically results in only a two- to fourfold increase in NO production above basal levels and in low levels of the measured stable by-products, $\mathrm{NO}_{2}{ }^{-}$and $\mathrm{NO}_{3}{ }^{-}$ $\left(\mathrm{NO}_{\mathrm{x}}\right)$. This low level of biologically active NO has made attempts to study its role in the liver technically difficult, particularly attempts to correlate changes in portal pressure with changes in measured levels of NO.

In light of the potential importance of eNOS-derived NO production in the liver and its role in hepatic blood flow regulation, the aims of this study are to $(a)$ determine the subcellular localization of eNOS in isolated SEC from the rat liver, (b) examine the flow-mediated release of $\mathrm{NO}$ from cultured SEC 
and in the isolated perfused rat liver (IPRL), (c) determine whether a measurable reduction in NO release is accompanied by an increase in hepatic perfusion pressure in the IPRL, and (d) examine the cellular distribution of eNOS in the intact rat liver.

\section{Methods}

Isolation and culture of SEC. SEC were isolated from normal Sprague-Dawley rats using a modification of the technique described by Bronk and Gores (22). In brief, the liver was digested in situ with a collagenase perfusion. The digest was filtered, and the hepatocytes were removed by centrifugation at $100 \mathrm{~g}$. The supernatant, which contained the nonparenchymal cells, was passed through a hydrogen peroxide-sterilized centrifugal elutriator rotating at 2,500 rpm to allow separation of endothelial cells from Kupffer cells. The elutriation fractions containing endothelial cells were centrifuged at $350 \mathrm{~g}$ and plated onto tissue culture plasticware coated with type IV human placental collagen (Sigma Chemical Co., St. Louis, MO). Alternatively, for immunocytochemical studies and shear stress experiments, SEC were plated onto collagen-coated glass slides. Glass slides for shear stress experiments were pretreated with $0.5 \mathrm{~N} \mathrm{NaOH}$ and autoclaved before use. SEC were plated and cultured in DME containing 1:7 concentration of Amniomax serum supplement, both obtained from GIBCO BRL (Gaithersburg, MD).

SEC characterization. SEC were characterized by immunocytochemistry, using two endothelial cell markers, vWf and the uptake of di-I-acetylated LDL, and additionally by transmission electron microscopy (TEM). After overnight culture, isolated SEC were fixed with $1.5 \%$ paraformaldehyde for $10 \mathrm{~min}$. Cells were washed, blocked, and immunostained with an $\mathrm{mAb}$ to vWf (DAKO Corp., Carpenteria, CA). After further blocking and incubation with a secondary antibody, slides were mounted with Slowfade (Molecular Probes, Inc., Eugene, OR) and visualized by immunofluorescence microscopy (Microphot-FXA; Nikon Inc., Melville, NY). Staining for di-I-acetylated LDL was performed as described by the manufacturer (Biomedical Technologies, Inc., Stoughton, MA). TEM was performed in freshly isolated SEC and in cells after $20 \mathrm{~h}$ in culture using a fixation method described previously (23). In brief, cells were fixed for $2 \mathrm{~h}$ in $2.5 \%$ glutaraldehyde and $1.0 \%$ paraformaldehyde in $0.1 \mathrm{~mol} /$ liter cacodylate buffer. Samples were then postfixed for $1 \mathrm{~h}$ in $1.0 \%$ osmium tetroxide, dehydrated in ethanol, and embedded in epon. Thin sections were stained with uranyl acetate and lead citrate and viewed with a microscope (model EM 10; Carl Zeiss, Inc., Thornwood, NY).

Western blotting. Cultured SEC were scraped in HBSS, and the pellet was homogenized in a lysis buffer $(50 \mathrm{mM}$ Tris- $\mathrm{HCl}, 0.1 \mathrm{mM}$ EGTA, $0.1 \%$ (vol/vol) $\beta$-mercaptoethanol, containing $100 \mathrm{mM}$ leupeptin, $1 \mathrm{mM}$ PMSF, $1 \%$ (vol/vol) NP-40, pH 7.5). After removing unbroken cells by centrifugation at $1,000 \mathrm{~g}$, the supernatant was boiled in Laemmli loading buffer and separated by SDS-PAGE on a $7.5 \%$ acrylamide gel. Proteins were electroblotted onto nitrocellulose, and the membranes were washed in Tris-buffered saline with $0.1 \%$ Tween and blocked in $5 \%$ milk as described previously (5). Membranes were subsequently incubated with an $\mathrm{mAb}$ to eNOS (Transduction Laboratories, Lexington, KY), and proteins were detected with a horseradish peroxidase-labeled anti-rabbit secondary antibody followed by enhanced chemiluminescence.

Confocal immunofluorescence microscopy. Immunofluorescence microscopy was performed using the eNOS antibody identical to that used for Western blotting. This antibody, at the dilutions used (1:100), does not recognize iNOS or neuronal NO synthase. For double-labeling immunofluorescence, cells were incubated with a polyclonal antibody for cis/media-Golgi protein (mannosidase II), and the eNOS mAb as described (5). The primary antibodies were detected using FITC- or Texas Red-coupled secondary antibodies. Slides were visualized using a confocal microscope (MRC 600; Bio-Rad Laboratories, Hercules, CA).
Shear stress apparatus. SEC were cultured onto $75 \times 38$-mm glass slides (Fisher Scientific Co., Pittsburgh, PA). The day after culture, SEC were washed with HBSS, and slides were mounted onto a parallel-plate flow chamber identical to the apparatus described originally by Frangos et al. (24). In this apparatus, flow is generated through the chamber by the hydrostatic pressure of the perfusate reservoir and maintained by recirculation of the perfusate from the lower to the upper reservoir. Shear stress is calculated using the following formula:

$T=6 Q \mu / b h^{2}$,

where $Q$ is the flow rate $\left(\mathrm{cm}^{3} / \mathrm{s}\right), \mu$ is the viscosity $\left(0.01\right.$ dynes $\left.\cdot \mathrm{s} / \mathrm{cm}^{2}\right)$, $h$ is the chamber channel height, $b$ is the chamber slit width $(2.5 \mathrm{~cm})$, and $T$ is the shear stress $\left(\right.$ dynes $\left./ \mathrm{cm}^{2}\right)$. Medium was circulated in the shear stress apparatus for $30 \mathrm{~min}$ before mounting the cells in the chamber. $\mathrm{NO}_{\mathrm{x}}$ levels were measured before and after this time to confirm that the shear stress apparatus was not releasing $\mathrm{NO}_{\mathrm{x}}$ into the medium. Cells were exposed to a shear stress of $14.1 \mathrm{dynes} / \mathrm{cm}^{2}$ for 30 min. Control cells were maintained in an incubator with identical temperature, $\mathrm{pH}$, and medium as cells exposed to flow. For $\mathrm{NO}_{\mathrm{x}}$ measurements from SEC exposed to flow, 0.1-ml samples were obtained from the $10 \mathrm{ml}$ of recirculating perfusate reservoir $30 \mathrm{~min}$ after the application of shear stress. For $\mathrm{NO}_{\mathrm{x}}$ measurements in control cells, $0.1-\mathrm{ml}$ samples were obtained after $30 \mathrm{~min}$ of incubation. Samples were analyzed using the NO-specific chemiluminescence analyzer as described below.

IPRL preparation. Male Sprague-Dawley rats (Harlan Sprague Dawley Inc., Indianapolis, IN) weighing 275-425 g were used for these experiments. The liver was perfused in situ via the portal vein, using a recirculating system based on modifications of a previously described technique (14). The rat was anesthetized with ketamine hydrochloride (Ketlar, $100 \mathrm{mg} / \mathrm{kg}$ body wt; Parke-Davis, Avon, CT), the abdomen was opened, and the bile duct was cannulated with PE-10 tubing (internal diameter $0.28 \mathrm{~mm}$ ). The hepatic artery was ligated, a ligature was passed around the inferior vena cava (IVC) above the renal veins, and the IVC was injected with $500 \mathrm{U}$ of heparin. The portal vein was cannulated with a $16-\mathrm{G}$ Teflon catheter after which the liver was perfused with Krebs solution ( $118 \mathrm{mM} \mathrm{NaCl}, 4.7 \mathrm{mM} \mathrm{KCl}, 1.2 \mathrm{mM}$ $\mathrm{KH}_{2} \mathrm{PO}_{4}, 1.2 \mathrm{mM} \mathrm{MgSO}$, $2.5 \mathrm{mM} \mathrm{CaCl}, 25 \mathrm{mM} \mathrm{NaHCO}, 11 \mathrm{mM}$ glucose, $2 \mathrm{U} / \mathrm{ml}$ heparin, $\mathrm{pH} 7.4$ ) oxygenated with $95 \% \mathrm{O}_{2} / 5 \% \mathrm{CO}_{2}$ at $37^{\circ} \mathrm{C}$. The IVC was cut below the ligature, thus allowing the perfusate to escape. The supradiaphragmatic portion of the IVC was cannulated with a 14-G Teflon catheter, and the ligature around the suprarenal IVC was tied. The liver was then perfused through the portal vein, and the effluent escaped through the IVC cannula. The liver was perfused until the effluent was clear. The preparation was then transferred to a Plexiglas, temperature-controlled $\left(37^{\circ} \mathrm{C}\right)$ perfusion chamber (Yale University Medical Instruments, New Haven, CT), and the liver was perfused with Krebs solution. The perfusate was recirculated at a constant rate of $40 \mathrm{ml} / \mathrm{min}$ using a peristaltic pump (Minipuls III; Gilson, Inc., Middleton, WI). The perfusion pressure was measured, continuously monitored with a Universal quartz transducer (model HPI1290C; Hewlett-Packard Co., Andover, MA) attached to a sidearm placed just proximal to the perfusion cannula, and recorded with a polygraph (model 7D; Grass Instrument Co., Quincy, MA). The preparation was allowed to stabilize for $10 \mathrm{~min}$. Perfusions were performed in normal animals with $\mathrm{N}$-monomethylL-arginine (L-NMMA) (Sigma Chemical Co.) at a concentration of $4 \times$ $10^{-4} \mathrm{M}$ or vehicle. L-NMMA was added to the perfusate reservoir 5 min after the recirculating system was established. The perfusate volume was $100 \mathrm{ml} .0 .6-\mathrm{ml}$ perfusate samples were obtained at 10 and 40 min after the recirculating system was established and analyzed for $\mathrm{NO}_{\mathrm{x}}$ using the NO-specific chemiluminescence analyzer (model NOA 270B; Seivers, Boulder, CO).

The global viability was assessed by standard criteria: gross appearance, stable $\mathrm{pH}$ of the perfusate ( $\mathrm{pHydrion}$ papers; Micro Essential Laboratory, Inc., Brooklyn, NY), stable perfusion pressure for 10 $\mathrm{min}$, and bile flow of $>1 \mu \mathrm{l} / \mathrm{min} / \mathrm{g}$ liver. 
Measurement of $\mathrm{NO}_{x}$ release. $\mathrm{NO}_{\mathrm{x}}$ (the sum of $\mathrm{NO}$ breakdown products $\mathrm{NO}_{2}{ }^{-}, \mathrm{NO}_{3}{ }^{-}$, and nitrosothiols) release was measured in samples using the NO-specific chemiluminescence analyzer as described previously (25). Briefly, samples were refluxed in $0.1 \mathrm{M}$ vanadium chloride in $2 \mathrm{M} \mathrm{HCl}$. These conditions reduce $\mathrm{NO}_{2}{ }^{-}$and $\mathrm{NO}_{3}{ }^{-}$ to $\mathrm{NO}$, which is quantified by a chemiluminescence detector after reacting with ozone. A calibration curve was constructed based on chemiluminescence peaks obtained with known standards of $\mathrm{NO}_{3}$. To standardize $\mathrm{NO}_{\mathrm{x}}$ release in experiments from isolated SEC, cells were scraped from the slides and lysed in $1 \mathrm{M} \mathrm{NaOH}$, and total protein was determined using the Bradford method.

Immunohistochemistry for eNOS. Rat liver was washed in PBS and fixed in formalin for $6 \mathrm{~h}$, after which it was embedded in paraffin. Tissue was sectioned and deparaffinized. Slides were pressurecooked in $0.01 \mathrm{~mol} /$ liter citrate buffer as described previously (26). Slides were incubated overnight with the $\mathrm{mAb}$ for eNOS identical to that used for immunofluorescence staining, and secondary staining was performed with horse anti-mouse (Vector Laboratories, Inc., Burlingame, CA) for $30 \mathrm{~min}$. After labeling with Streptavidin peroxidase (Boehringer Mannheim Biochemicals, Indianapolis, IN), slides were developed with diaminobenzene tetrachloride. Negative control slides were incubated with serum substituted for the primary antibody.

Statistical analysis. All data are given as mean \pm SEM. Statistical analysis was performed using two-way ANOVA and paired Student's $t$ test where appropriate. $P<0.05$ was considered significant.

\section{Results}

Isolation and characterization of SEC. To examine eNOS regulation in SEC, it was necessary to isolate and culture a pure population of SEC. Collagenase-digested livers which were subjected to a series of filtering steps, centrifugation, and centrifugal elutriation resulted in preparations that were highly enriched with SEC. The purity of the preparation procedure was determined by several parameters, which included the following: uptake of fluorescent di-I-acetylated LDL (Fig. $1 B$ ), the characteristic cobblestone morphology of endothelial cells under phase-contrast microscopy (Fig. $1 A$ ), the presence of vWf (Fig. $1 C$ ), and TEM (Fig. 2). There is some disagreement in the literature as to whether SEC express vWf, with results varying depending on the antibody used and the duration of time SEC are cultured before immunostaining (27). We find that SEC stain for vWf in a specific and reproducible manner when stained the day after plating. Our findings of vWf staining in SEC are consistent with those of several other authors (28-31). Based on the described parameters, our isolation procedure resulted in a purity of SEC which reached $95 \%$ or greater as determined in five individual isolations. Ultrastructural characterization was performed using TEM to evaluate the presence of fenestrae in SEC. TEM was performed in

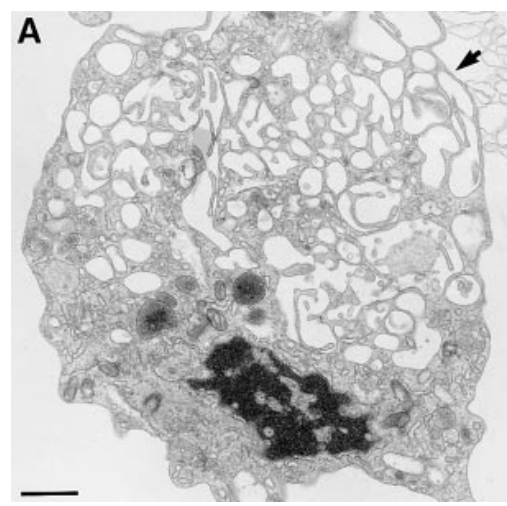

Figure 2. Ultrastructural characterization of SEC. Freshly isolated SEC and SEC cultured for $20 \mathrm{~h}$ were fixed, stained, and visualized by TEM. $(A)$ In freshly isolated SEC, there is a

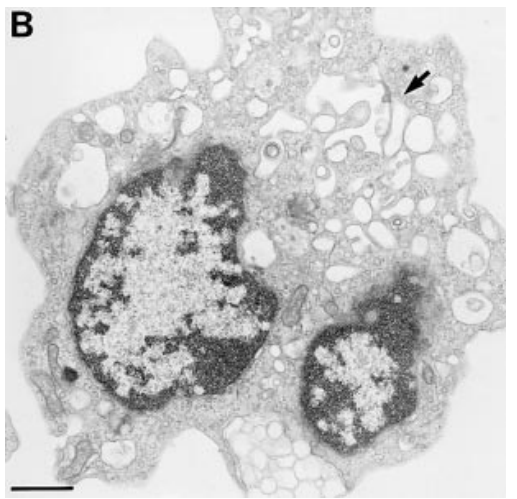
classic sponge-like appearance due to the retracting of fenestrae in sieve plates (arrow). (B) In cultured SEC, collapsed fenestrae are present, as detected by the vacuole-like structures (arrow). Fenestrae are present in less abundance in SEC cultured for $20 \mathrm{~h}$ compared with freshly isolated SEC. Bar, $1.0 \mu \mathrm{m}$.

freshly isolated cells and in cells cultured for $20 \mathrm{~h}$. Fenestrae were present in cells at both time points, although they appeared more prominent in freshly isolated cells (Fig. 2, $A$ and $B)$. These findings are in agreement with previously described analyses of fenestrae in SEC (32-35).

Characterization and subcellular localization of eNOS in isolated SEC. Based on the important role that NO may play in the regulation of hepatic vascular resistance, we proceeded to examine the expression of eNOS in SEC by Western blotting and to determine the subcellular localization of the enzyme by confocal immunofluorescence microscopy. On Western blot, a single band was seen at $135 \mathrm{kD}$ that corresponded to the predicted electrophoretic mobility of eNOS (Fig. $3 \mathrm{~A}$ ). By loading $<50 \mu \mathrm{g}$ protein/well, a single band could be obtained, suggesting that there are abundant quantities of eNOS protein in SEC. Using confocal immunofluorescence microscopy to examine the subcellular localization of the enzyme, eNOS appeared in a predominantly juxtanuclear pattern. To confirm the nature of this juxtanuclear staining, double fluo-
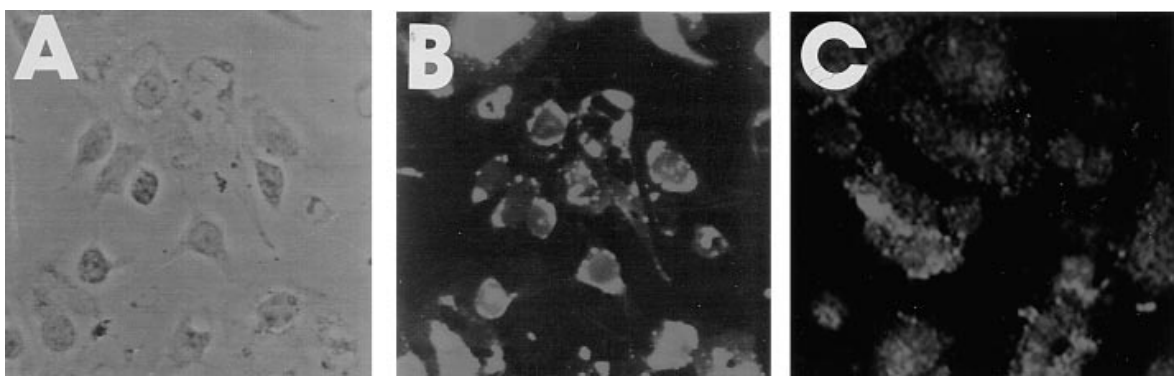

Figure 1. Characterization of isolated SEC. SEC were isolated and cultured onto glass slides. The next day, cells were prepared for immunofluorescence microscopy as described in Methods. (A) SEC are viewed under phase-contrast microscopy, revealing a characteristic endothelial cell morphology. (B) The identical field from $A$ depicts the endocytosis of di-I-acetylated LDL, a characteristic of endothelial cells. (C) SEC also stain positive for vWf by immunofluorescence microscopy. 
A

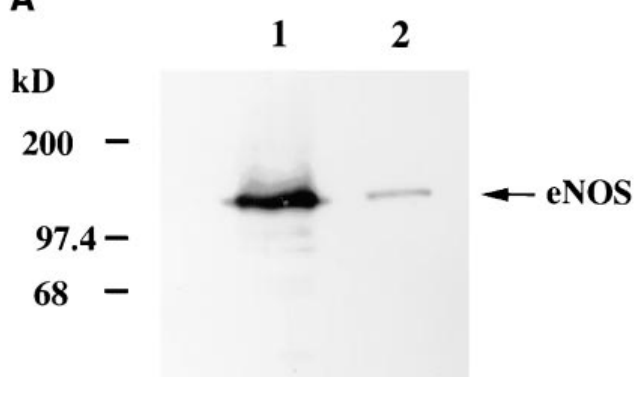

B

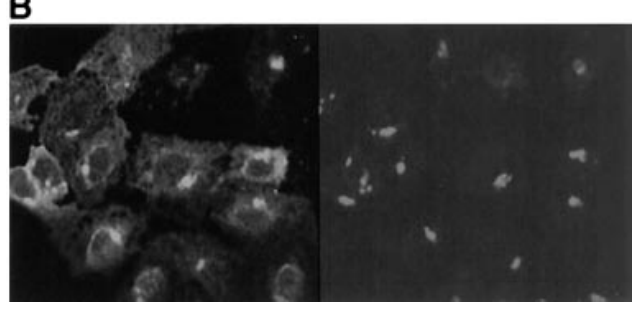

Figure 3. eNOS expression and subcellular localization in SEC. (A) HEK cells expressing eNOS (lane 1) and SEC lysates (lane 2) were prepared for Western blotting, and eNOS was detected with an $\mathrm{mAb}$. (B) SEC were isolated and cultured onto glass slides, labeled with an $\mathrm{mAb}$ for eNOS and a polyclonal antibody for mannosidase II, a cis/mediaGolgi protein, and visualized by confocal immunofluorescence microscopy. The majority of eNOS protein (right) colocalizes with mannosidase II (left), indicating that the enzyme resides predominantly in the cis/media-Golgi membranes in SEC (original magnification $\times 630$ ).

rescent labeling experiments were performed. eNOS in SEC colocalized with mannosidase II, a marker protein for cis/media-Golgi membranes (Fig. $3 \mathrm{~B}$ ), confirming that eNOS protein is localized predominantly to the cis/media-Golgi of SEC. Immunofluorescence staining in SEC with a polyclonal antibody to caveolin, the coat protein of caveolae, resulted in a weak stain compared with other cells that contain caveolae in abundance, such as bovine lung microvascular cells and NIH 3 T3 cells (36), suggesting that there are small amounts of this protein in SEC (data not shown). This low level staining precluded colocalization experiments with eNOS.

Flow-mediated release of NO from cultured SEC. Although eNOS is expressed constitutively, biomechanical forces such as flow and shear stress modulate eNOS gene expression and NO production (7-9). To determine whether flow could regulate eNOS-derived NO production in the hepatic microcirculation, an in vitro apparatus was used that allowed for the measurement of $\mathrm{NO}_{\mathrm{x}}$ release from a pure population of isolated cells. In these experiments, SEC were isolated and cultured and then mounted in the parallel-plate flow chamber. Cells were studied $20 \mathrm{~h}$ after isolation. There was no measurable increase in $\mathrm{NO}_{\mathrm{x}}$ release in cells that were not exposed to shear stress (Fig. 4). Exposure of SEC to $14.1 \mathrm{dynes} / \mathrm{cm}^{2}$ of shear stress resulted in a significant increase in $\mathrm{NO}_{\mathrm{x}}$ release in cells exposed to flow after $30 \mathrm{~min}$ (Fig. 4).

$N O_{x}$ accumulation in the perfused liver and effects of NOS inhibition on portal pressure. Prior studies designed to address the role of NO in the hepatic circulation have met with varied results $(14,18,21)$. These studies used methodologies in which NO biosynthesis inhibitors were administered to rats in vivo or in the perfused liver, and effects were examined by assessing changes in portal pressure, hepatic vascular resistance, or sinusoidal diameter; however, the measurement of a reduction in $\mathrm{NO}_{\mathrm{x}}$ levels in response to the NO biosynthesis inhibitor could not be demonstrated (21). To allow for the measurement of $\mathrm{NO}$ accumulation in the perfused liver and to assess the effects of $\mathrm{NO}$ biosynthesis inhibition on $\mathrm{NO}_{\mathrm{x}}$ and portal pressure, an IPRL model with a low volume of perfusate $(100 \mathrm{ml})$ was used. In this experimental preparation, during perfusion at a constant flow rate, $\mathrm{NO}_{\mathrm{x}}$ cumulative concentration was measured in the perfusate. Normal livers perfused at a flow rate of $40 \mathrm{ml} / \mathrm{min}$ $(n=5)$ demonstrated a significant increase in $\mathrm{NO}_{\mathrm{x}}$ concentration in the liver perfusate (Fig. $5 A$ ), thus demonstrating that there is cumulative $\mathrm{NO}_{\mathrm{x}}$ production from SEC in the hepatic sinusoids. To confirm that the $\mathrm{NO}_{\mathrm{x}}$ measured was indeed a re- sult of NO biosynthesis, and to assess the effects of reduced $\mathrm{NO}_{\mathrm{x}}$ concentration on portal pressure, experiments were performed in the presence of L-NMMA. In these experiments, treatment of perfused livers with L-NMMA $(n=6)$ decreased significantly $\mathrm{NO}_{x}$ concentration compared with control livers at 10 and $40 \mathrm{~min}(P<0.05)$ (Fig. $5 A)$. Concomitant with the reduced $\mathrm{NO}_{\mathrm{x}}$ concentrations observed in the animals treated with L-NMMA, the portal pressure in these animals was significantly higher at all times versus normal control animals $(P<$ 0.05) (Fig. 5 B).

Cellular distribution of eNOS in the liver. There is some disagreement as to whether hepatocytes and other nonendothelial hepatic cells express eNOS in the liver (37). To address the question of cellular distribution of eNOS in the liver, immunostaining of intact liver sections was performed. Immunostaining revealed eNOS expression along the endothelial cells lining the sinusoids, but no significant hepatocyte staining was found (Fig. 6). No staining was seen in negative control slides in which serum was substituted for the primary antibody, or in

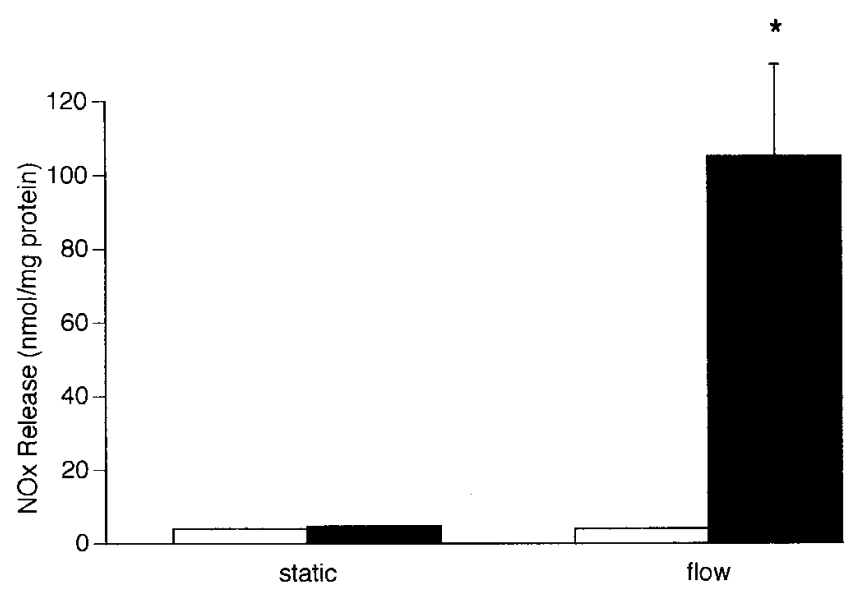

Figure 4. Release of $\mathrm{NO}_{\mathrm{x}}$ from SEC exposed to shear stress. Cultured SEC were mounted into parallel-plate flow chambers and exposed to 14.1 dynes $/ \mathrm{cm}^{2}$ of shear stress for 30 min (black bars). No significant increase in $\mathrm{NO}_{\mathrm{x}}$ was observed in control cells, which were not exposed to shear stress (white bars). There was a significant increase in accumulated $\mathrm{NO}_{\mathrm{x}}$ in the perfusate of cells exposed to flow for $30 \mathrm{com}-$ pared with $0 \min ($ mean $\pm \mathrm{SEM} ; n=5 ; * P<0.05)$. 
A

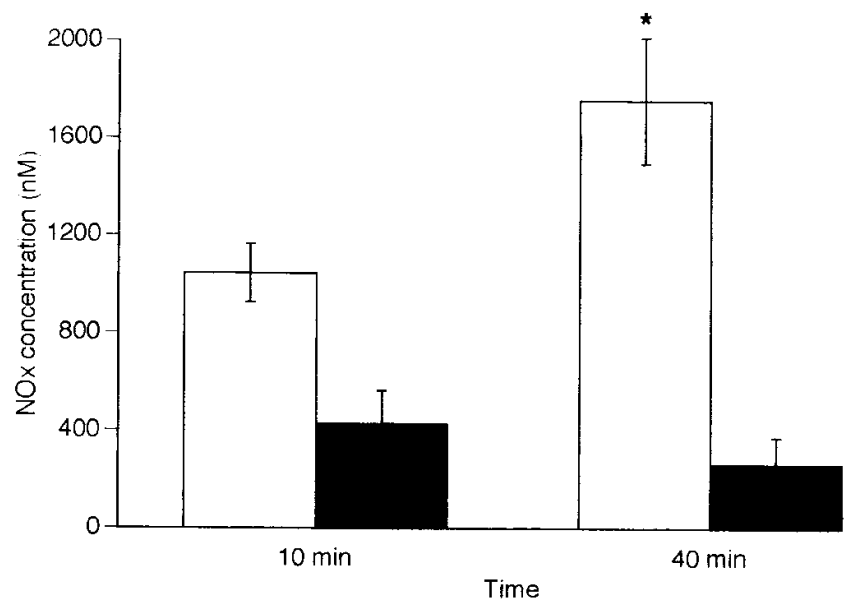

B

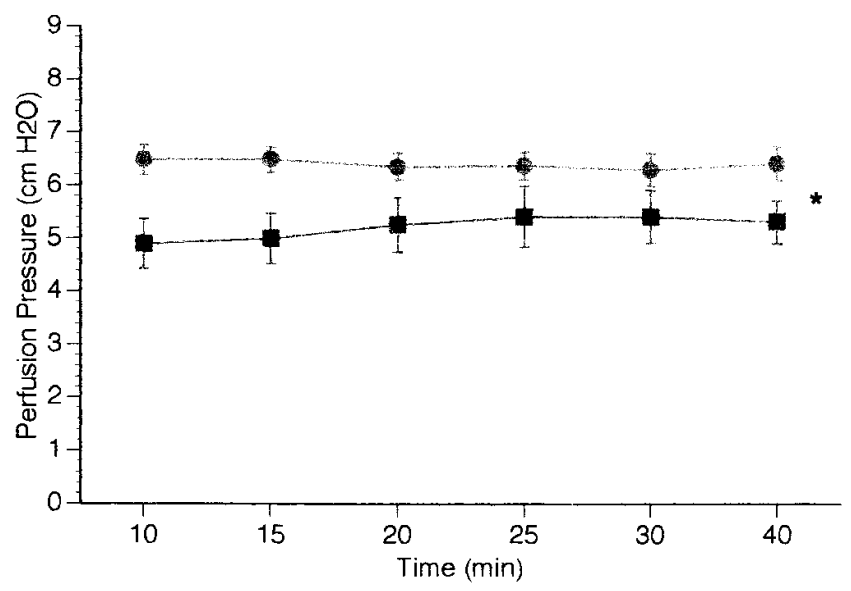

Figure 5. $\mathrm{NO}_{\mathrm{x}}$ accumulation in the IPRL model and corresponding portal perfusion pressure. Rat livers were perfused in situ, and $\mathrm{NO}_{\mathrm{x}}$ release from the vasculature was assessed by NO-specific chemiluminescence in experiments with and without perfusion with L-NMMA. $(A)$ With a progressive increase in duration of flow, there was a significant increase in $\mathrm{NO}_{\mathrm{x}}$ in the perfusate (white bars) when sampled at 10 and $40 \mathrm{~min}$ after the stabilization of the preparation $(P<0.01)$. This increase was blocked by the addition of L-NMMA to the perfusate (black bars) at both time points. (B) Portal perfusion pressure was increased significantly in livers that were perfused in the presence of L-NMMA (gray circles) compared with control livers (black squares) throughout all time points examined (ANOVA $P<0.05$ ).

sections incubated with secondary antibody alone (data not shown).

\section{Discussion}

The role of endogenous NO as a modulator of hepatic vascular tone and the determination of potential regulatory mechanisms are an important area of investigation, as these mechanisms may play a role in the pathogenesis of vascular diseases of the liver. This study indicates that isolated SEC express eNOS protein in abundant quantities, and that the enzyme is localized primarily to the Golgi region in these cells. Basal NO release from SEC occurs at a low levels, and cultured SEC re- spond to shear stress with an increase in NO release. These findings were then investigated in the intact organ, in which $\mathrm{NO}_{\mathrm{x}}$ concentration increases in relation to time during liver perfusion. The administration of L-NMMA in the perfused liver results in a measurable reduction in NO release, concomitant with an increase in portal pressure. Thus, the increase in $\mathrm{NO}_{\mathrm{x}}$ concentration is most likely due to the release of $\mathrm{NO}$ from SEC in response to perfusate flow. Based on immunohistochemical staining, the predominant expression of eNOS occurs in SEC. Thus, this study demonstrates unequivocally that eNOS in SEC is responsive to physiological regulation by flow and shear stress, thereby supporting the concept that NO is a major regulator of intrahepatic resistance.

Prior studies have demonstrated the presence of eNOS transcripts and protein in several cell types, including endothelial cells, cardiac myocytes, platelets, and hippocampal neurons (38-41). Regardless of the cell type, most of these studies have found that eNOS segregates in the particulate fraction of cell lysates. This membrane association appears to be dependent on the $N$-myristolation of the enzyme (42). However, the precise subcellular localization of eNOS varies in endothelial cells isolated from different vascular beds, and may depend on the abundance of caveolae. In endothelial cells with an abundance of caveolae, such as bovine lung microvascular cells, eNOS is readily detectable by microscopy and subcellular fractionation in caveolae and Golgi (36). This is in contrast to eNOS in human umbilical vein endothelial cells, and bovine aortic endothelial cells which demonstrate very low amounts of eNOS in caveolae, with the majority of the enzyme in Golgi membranes (5). Studies examining subcellular localization of eNOS in cardiac myocytes by Balligand et al. do not find a significant amount of perinuclear staining, suggesting that Golgi localization is minimal, although double-labeling experiments were not performed in this study (41). Thus, the subcellular localization of eNOS may be influenced by the biological characteristics of the endothelial cell type in which it is expressed and

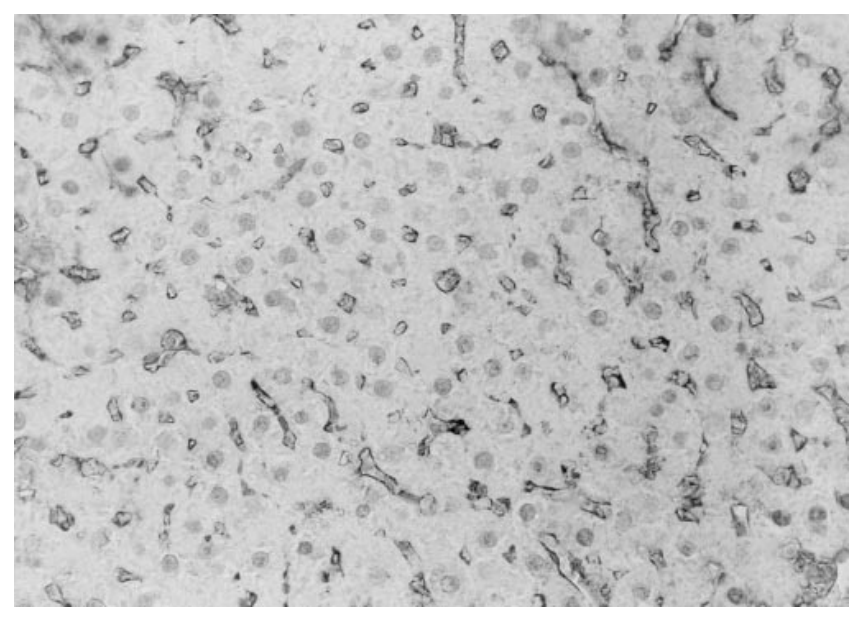

Figure 6. Immunohistochemical staining of eNOS in rat liver. Rat liver was fixed in formalin for $6 \mathrm{~h}$ and embedded in paraffin. Tissue was sectioned, deparaffinized, and pressure-cooked as described in Methods. Slides were incubated overnight with an mAb for eNOS. Peroxidase staining is visualized in cells lining the hepatic sinusoids (original magnification $\times 200$ ). Slides that were incubated with serum substituted for the primary antibody showed no staining (data not shown). 
the function of NO in the specific organ being studied. This study demonstrates that SEC express eNOS protein that is localized predominantly in the cis/media-Golgi region. In our study, SEC appear to express barely detectable levels of caveolin, the coat protein for the organelle caveolae. In prior studies by Palade and colleagues, vascular tissue in visceral organs such as the liver were found to have low amounts of non-clathrin-coated vesicles of $50-100 \mathrm{~nm}$ in diameter, recognized recently as caveolae (43). As the subcellular targeting of eNOS affects NO release (5), the specific localization of eNOS in SEC may influence NO production in the hepatic circulation.

A major force regulating the biological responses of endothelial cells is flow and the concomitant development of shear stress, the frictional force applied to endothelial cells by the flow of viscous fluid through a vessel lumen (7-9). The magnitude of shear forces varies greatly, from the terminal arteriole, where forces have been estimated to be $60 \mathrm{dynes} / \mathrm{cm}^{2}$, to the venules, where forces are $<10 \mathrm{dynes} / \mathrm{cm}^{2}$ (44). However, the precise level of shear stress will vary depending on the flow rate, vessel diameter and geometry, red cell gradient, and the vascular bed (45). Most of the studies examining the effects of shear stress on vascular endothelium have focused on arterial vasculature, due to the higher levels of shear stress present in these beds compared with venous beds. The portal vasculature, as an entirely venous system, is likely to have lower levels of endothelial shear stress than arteriolar levels; however, there are appreciably large shear forces present in microcirculatory beds such as the hepatic sinusoids (45). In these vessels, although the flow rate through individual sinusoids may be low, the narrow vessel caliber results in elevated levels of shear stress. In the hepatic sinusoids, physiologic modulations in sinusoidal diameter may occur through mechanisms such as HSC contraction, and thus give rise to even greater levels of shear stress. This study indicates that SEC respond to such increases in flow with increased NO production, using cultured SEC exposed to flow in a parallel-plate flow chamber. In the intact perfused liver, $\mathrm{NO}_{\mathrm{x}}$ accumulation is observed, the production of which is inhibited by L-NMMA. Each of these methods has distinct advantages. The parallel-plate flow chamber allows for the determination of the effects of flow on a pure population of endothelial cells with no contamination from other liver cell types. Additionally, this apparatus allows for the precise determination of the amount of shear stress to which SEC are exposed. The IPRL system allows for the determination of $\mathrm{NO}_{\mathrm{x}}$ production from $\mathrm{SEC}$ in a system more akin to that in vivo. Additionally, it avoids potential confounding variables related to SEC isolation and culture. Flow-mediated NO release in the hepatic microcirculation may be a primary mechanism which allows for the regulation of flow and resistance in the liver. Alternatively, this may be a compensatory mechanism, whereby SEC are able to autoregulate the level of shear stress to which they are exposed. By releasing $\mathrm{NO}$ in response to increases in shear stress, the sinusoid may dilate, resulting in an increase in vessel caliber, and thus normalize the level of shear stress to which SEC are exposed.

The mechanotransduction signaling pathway whereby eNOSderived NO is released by endothelial cells in response to biomechanical stimuli is an area of current investigation. Recent reports suggest that tyrosine kinase signaling pathways may play a role in modulating the shear stress-mediated increase in NO release. Ayajiki et al. found that tyrosine kinase inhibitors attenuate the shear stress-induced release in NO, and that cer- tain tyrosine-phosphorylated cellular proteins increase in response to the duration of shear stress (9). However, studies to date do not suggest that the degree to which eNOS itself is tyrosine phosphorylated is affected by shear stress. Kuchan and Frangos have shown that the initial and more pronounced increase in NO release occurs in response to an initiation or increase in shear stress, and that this increase in NO release occurs in a calcium-dependent manner (8). This phase is followed by a more gradual increase in NO release in response to continued shear stress which occurs in a calcium-independent manner (8). As the NO release measured in our parallel-plate flow chamber and our IPRL model occurs in response to the initiation of flow, the NO release we detect is likely to be calcium dependent.

NO has clearly been shown to play an important hemodynamic role in different models of hepatic microcirculatory disturbances. In the endotoxemic mouse, L-NMMA decreases hepatic sinusoidal diameter (16). In the endotoxemic rat, this agent reverses the reduction in vasoconstrictive response to phenylephrine (46). These studies suggest that NO plays an important role in protecting against the hemodynamic effects of liver injury. However, in these conditions, the hemodynamic effects of NO are likely mediated through iNOS induction. Every major cell type in the liver has the ability to produce NO through iNOS induction, given the appropriate conditions. These conditions generally involve liver injury and/or inflammation, with the subsequent induction of TNF- $\alpha$, IL- $1 \beta$, and IFN- $\gamma$, cytokines that all have the potential to induce iNOS $(10,47,48)$. Such induction is unlikely to occur in normal conditions, during which eNOS-derived NO production predominates. Although experimental evidence suggests that endogenous NO regulates normal vascular tone in other vascular beds $(1,2)$, the role of basal NO production as a mediator of normal hepatic vascular tone has met with discordant results. Recently, Mittal et al. found that NNA, an NO biosynthesis inhibitor, increases portal pressure in normal rat livers perfused in situ (14). The maximal response of the vasoconstrictor norepinephrine was enhanced by NNA (14). L-arginine, the substrate for the production of NO, abolished these effects of NNA on the vasoconstrictive response of norepinephrine (14). Oshita et al. have found that L-NMMA enhances significantly the hepatic vasoconstrictive effects of intraportal administration of ethanol, supporting the role of endogenous $\mathrm{NO}$ as a modulator of intrahepatic resistance (49). However, Suematsu et al., using the NO biosynthesis inhibitors nitro-L-arginine methyl ester and aminoguanidine in the perfused rat liver, found that NO inhibition did not affect portal vascular resistance (21). However, in this study, levels of NO were not measured, and, therefore, it could not be certain whether the NO biosynthesis inhibitors were actually reducing the endogenous levels of NO. By demonstrating that a measurable reduction in basal and flow-mediated NO levels results in an increase in portal pressure, our study provides strong evidence that endogenous NO contributes in a physiologically relevant manner to basal vascular tone in the liver.

What is the precise site of resistance changes in the normal liver? Although the microvasculature does not play a role in resistance changes in most organ beds, there is strong experimental evidence to suggest that the sinusoids do function as liver-resistance vessels. This evidence includes $(a)$ pressure measurements using liver micropuncture, $(b)$ anatomical studies using intravital microscopy, and (c) functional data in HSC 
demonstrating the contractile phenotype of these cells. Nakata et al. have performed direct measurements of blood pressure in blood vessels of the rat liver by micropuncture techniques $(50,51)$. Their studies indicate that there is a steep pressure gradient between the portal venules and central vein, suggesting that there is high resistance in the sinusoidal microvasculature that lies between these sites (50). McCuskey (52) and Clemens and colleagues (53) have demonstrated independently by intravital microscopy that vasoactive agents modulate the patency of the sinusoidal lumen and thus mediate blood flow. Although SEC, Kupffer cells, and HSC all possess contractile proteins (54), changes in sinusoidal lumen can be demonstrated most clearly at sites that colocalize with HSC (53). Several investigators have performed functional studies in HSC demonstrating the ability of these cells to relax and contract in response to vasoactive agents such as NO, in vivo and in vitro, suggesting that these cells may modulate resistance in a manner similar to smooth muscle cells in arteriolar sphincters in other sites $(15,53,55-57)$. In arteriolar resistance vessels, abluminal NO release from endothelial cells acts in a paracrine fashion on the underlying smooth muscle layer. NO diffuses into smooth muscle cells and stimulates increases in soluble guanylate cyclase, thus increasing cGMP and activating a cellsignaling pathway which results in smooth muscle relaxation (4). As the vessels in the hepatic sinusoids contain no smooth muscle layer, it is tempting to speculate that basal and flowmediated NO release from SEC observed in our studies regulates portal pressure by modulating HSC whose perisinusoidal location is ideal for modulating sinusoidal diameter through contraction and relaxation.

In conclusion, our study determines the subcellular distribution of eNOS in isolated cells and in the intact organ. Our data indicate that SEC are the cell type responsible for the basal production of $\mathrm{NO}$ in the liver and release a greater amount of NO in response to flow, a response that is mediated through the activity of the eNOS isoform. Additionally, we provide strong evidence to support the role of endogenous NO as a mediator of hepatic vascular tone.

\section{Acknowledgments}

The authors acknowledge the technical assistance of Michelle Pate

This work is supported by the National Institutes of Health (grants HL-57665 and HL-51948 [W.C. Sessa]), a Veterans Affairs Merit Award (R.J. Groszmann) and the Cell Isolation and Morphology Core of the Yale Liver Center (P30 DK34989). W.C. Sessa is an Established Investigator of the American Heart Association. V. Shah is the recipient of a Postdoctoral Fellowship Award from the American Liver Foundation. V. Shah and F. Haddad are recipients of National Institutes of Health training grants.

\section{References}

1. Koizumi, T., R. Gupta, M. Banerjee, and J.H. Newman. 1994. Changes in pulmonary vascular tone during exercise. Effects of nitric oxide (NO) synthase inhibition, L-arginine infusion, and NO inhalation. J. Clin. Invest. 94:2275-2282.

2. Palmer, R.M.J., A.G. Ferrige, and S. Moncada. 1987. Nitric oxide accounts for the biological activity of endothelium-derived relaxing factor. $\mathrm{Na}$ ture. 327:524-526.

3. Ziche, M., L. Morbidelli, E. Masini, S. Amerini, H.J. Granger, C.A. Maggi, P. Geppetti, and F. Ledda. 1994. Nitric oxide mediates angiogenesis in vivo and endothelial cell growth and migration in vitro promoted by substance P. J. Clin. Invest. 94:2036-2044.

4. Sessa, W.C. 1994. The nitric oxide synthase family of proteins. J. Vasc. Res. 31:131-143.
5. Sessa, W.C., G. Garcia-Cardena, J. Liu, A. Keh, J.S. Pollock, J. Bradley, A. Thiru, I.M. Braverman, and K. Desai. 1995. The Golgi association of endothelial nitric oxide synthase is necessary for the efficient synthesis of nitric oxide. J. Biol. Chem. 270:17641-17644.

6. Liu J., G. Garcia-Cardena, and W.C. Sessa. 1996. Palmitoylation of endothelial nitric oxide synthase is necessary for optimal stimulated release of nitric oxide: implications for caveolae localization. Biochemistry. 35:13277-13281.

7. Ranjan, V., Z. Xiao, and S.L. Diamond. 1995. Constitutive NOS expression in cultured endothelial cells is elevated by fluid shear stress. Am. J. Physiol. 269:H550-H555.

8. Kuchan, M.J., and J.A. Frangos. 1994. Role of calcium and calmodulin in flow-induced nitric oxide production in endothelial cells. Am. J. Physiol. 266: C628-C636.

9. Ayajiki, K., M. Kindermann, M. Hecker, I. Fleming, and R. Busse. 1996. Intracellular $\mathrm{pH}$ and tyrosine phosphorylation but not calcium determine shear stress-induced nitric oxide production in native endothelial cells. Circ. Res. 78: $750-758$.

10. Rockey, D.C., and J.J. Chung. 1996. Regulation of inducible nitric oxide synthase in hepatic sinusoidal endothelial cells. Am. J. Physiol. 271:G260-G267.

11. Grossman, H.J., V.L. Grossman, and P.S. Bhatal. 1994. Intrahepatic vascular resistance in cirrhosis. In Portal Hypertension: Pathophysiology and Treatment. J. Bosch and R.J. Groszmann, editors. Blackwell Scientific Publications, London. 1-16.

12. McCuskey, R.S., and F.D. Reilly. 1993. Hepatic microvasculature: dynamic structure and its regulation. Semin. Liver Dis. 13:1-11.

13. Burt, A.D., B. LeBail, C. Balabaud, and P. Bioulac-Sage. 1993. Morphologic investigation of sinusoidal cells. Semin. Liver Dis. 13:21-37.

14. Mittal, M., T. Gupta, F. Lee, C. Sieber, and R.J. Groszmann. 1994. Nitric oxide modulates hepatic vascular tone in normal rat liver. Am. J. Physiol. 267:G416-G422.

15. Rockey, D.C., and J.J. Chung. 1995. Inducible nitric oxide synthase in rat hepatic lipocytes and the effect of nitric oxide on lipocyte contractility. $J$. Clin. Invest. 95:1199-1206.

16. Nishida, J., R.S. McCuskey, D. McDonnell, and E.S. Fox. 1994. Protective role of NO in hepatic microcirculatory dysfunction during endotoxemia. Am. J. Physiol. 267:G1135-G1141.

17. McCuskey, R.S. 1995. Does a toxic gas regulate hepatic sinusoidal blood flow? J. Clin. Invest. 96:2099.

18. Oshita, M.Y., S. Takei, H. Kawano, T. Yoshihara, H. Hijioka, M. Fukui, E. Goto, Y. Masuda, Y. Nishimura, H. Fusamato, and T. Kamada. 1993. Roles of endothelin-1 and nitric oxide in the mechanism for ethanol-induced vasoconstriction in the rat liver. J. Clin. Invest. 91:1337-1342.

19. Sakamoto, M., T. Ueno, M. Kin, H. Ohira, T. Torimura, S. Inuzuka, M. Sata, and K. Tanikawa. 1993. Ito cell contraction in response to endothelin-1 and substance P. Hepatology. 18:978-983.

20. Berti, F., P. Sogni, S. Cailmail, R. Moreau, B. Pipy, and D. Lebrec. 1993. Role of prostacyclin in hemodynamic alterations in conscious rats with extrahepatic or intrahepatic portal hypertension. Hepatology. 18:621-627.

21. Suematsu, M., N. Goda, T. Sano, S. Kashiwagi, T. Egawa, Y. Shinoda, and Y. Ishimura. 1995. Carbon monoxide: an endogenous modulator of sinusoidal tone in the perfused rat liver. J. Clin. Invest. 96:2431-2437.

22. Bronk, S.F., and G.J. Gores. 1991. Acidosis protects against lethal oxidative injury of the liver sinusoidal endothelial cells. Hepatology. 14:150-157.

23. Fallon, M.B., F.S. Gorelick, J.M. Anderson, A. Mennone, A. Saluja, and M.L. Steer. 1995. Effect of cerulein hyperstimulation on the paracellular barrier of rat exocrine pancreas. Gastroenterology. 108:1863-1872.

24. Frangos, J.A., L.V. McIntire, and S.G. Eskin. 1988. Shear stress induced stimulation of mammalian cell metabolism. Biotechnol. Bioeng. 32:1053-1060.

25. Archer, S. 1993. Measurement of nitric oxide in biological models. FASEB (Fed. Am. Soc. Exp. Biol.) J. 7:349-360.

26. Atucha, N., V. Shah, G. Garcia-Cardena, W.C. Sessa, and R.J. Groszman. 1996. Role of the endothelium in the abnormal response of mesenteric vessels in rats with portal hypertension and liver cirrhosis. Gastroenterology. 111:1627-1632.

27. Eyhorn, S., H.J. Schlayer, H.P. Henninger, P. Dieter, R. Hermann, M. Menker-Woort, H. Becker, H-E. Schaefer, and K. Decker. 1988. Rat hepatic sinusoidal endothelial cells in monolayer culture. J. Hepatol. 6:23-35.

28. Shaw, G.R., A.R. Johnson, W.W. Schulz, R.N. Zahlten, and B. Combes. 1984. Sinusoidal endothelial cells from normal guinea pig liver: isolation, culture and characterization. Hepatology. 4:591-602.

29. Soda, R., and M. Tavassoli. 1984. Insulin uptake by rat liver endothelium studied in fractionated liver cell suspensions. Mol. Cell. Biochem. 65:117123.

30. Reider, H., G. Ramadori, H.-P. Dienes, and K.-H. Buschenfelde. 1987. Sinusoidal endothelial cells from guinea pig liver synthesize and secrete cellular fibronectin in vitro. Hepatology. 7:856-864.

31. Gatmaitan, Z., L. Varticovski, L. Ling, R. Mikkelsen, A.-M. Steffan, and I.M. Arias. 1996. Studies on fenestral contraction in rat liver endothelial cells in culture. Am. J. Pathol. 148:2027-2041.

32. Irving, M.G., F.J. Roll, S. Huang, and D.M. Bissell. 1984. Characterization and culture of sinusoidal endothelium from normal rat liver: lipoprotein uptake and collagen phenotype. Gastroenterology. 87:1233-1247. 
33. Braet, F., R. DeZanger, T. Sasaoki, M. Baekeland, P. Janssens, B. Smedsrod, and E. Wisse. 1994. Assessment of a method of isolation, purification and cultivation of rat liver sinusoidal endothelial cells. Lab. Invest. 70:944952.

34. de Leeuw, A.M., R.J. Barelds, R. de Zanger, and D.L. Knook. 1982. Primary cultures of endothelial cells of the rat liver. Cell Tissue Res. 223:201-215.

35. Vidal-Vanaclocha, F., M. Rocha, A. Asumendi, and E. BarberaGuillem. 1993. Isolation and enrichment of two sublobular compartment-specific endothelial cell subpopulations from liver sinusoids. Hepatology. 18:328339.

36. Garcia-Cardena, G., P. Oh, J. Liu, J.E. Schnitzer, and W.C. Sessa. 1996. Targeting of nitric oxide synthase to endothelial caveolae via palmitoylation: implications for nitric oxide signaling. Proc. Natl. Acad. Sci. USA. 93:64486453.

37. Zimmermann, H., P. Kurzen, W. Klossner, E.L. Renner, and U. Marti. 1996. Decreased constitutive hepatic nitric oxide synthase expression in secondary biliary fibrosis and its changes after Roux-en-Y choledocho-jejunostomy in the rat. J. Hepatol. 25:567-573.

38. Palmer, R.M.J., D.S. Ashton, and S. Moncada. 1988. Vascular endothelial cells synthesize nitric oxide from L-arginine. Nature. 333:664-666.

39. Dinerman, J.L., T.M. Dawson, M.J. Schell, A. Snowman, and S.H. Snyder. 1994. Endothelial nitric oxide synthase localized to hippocampal pyramidal cells: implications for synaptic plasticity. Proc. Natl. Acad. Sci. USA. 91:42144218 .

40. Radomski, M.W., R.M.J. Palmer, and S. Moncada. 1987. Comparative pharmacology of endothelium-derived relaxing factor, nitric oxide and prostacyclin in platelets. Br. J. Pharmacol. 92:181-187.

41. Balligand, J.-L., L. Kobzik, X. Han, D.M. Kaye, L. Belhassen, D.S O'Hara, R.A. Kelly, T.W. Smith, and T. Michel. 1995. Nitric oxide-dependent parasympathetic signaling is due to activation of constitutive endothelial (type III) nitric oxide synthase in cardiac myocytes. J. Biol. Chem. 270:14582-14586.

42. Sessa, W.C., C.M. Barber, and K.R. Lynch. 1993. Mutation of $N$-myristoylation site converts endothelial nitric oxide synthase from a membrane to a cytosolic protein. Circ. Res. 72:921-924.

43. Simionescu, M., N. Simionescu, and G.E. Palade. 1974. Morphometric data on the endothelium of blood capillaries. J. Cell Biol. 60:128-152.

44. Lipowsky, H.H. 1995. Shear stress in the circulation. In Flow-dependent Regulation of Vascular Function. J.A. Bevan, G. Kaley, and G.M. Rubanyi, ed- itors. Oxford University Press, New York. 28-45

45. Lipowsky, H.H., S. Kovalcheck, and B.W. Zweifach. 1978. The distribution of blood rheological parameters in the microcirculation of cat mesentery. Circ. Res. 43:738-749.

46. Pastor, C.M., and T.R. Billiar. 1995. Nitric oxide causes hyporeactivity to phenylephrine in isolated perfused livers from endotoxin-treated rats. Am. J. Physiol. 268:G177-G182.

47. Feder, L.S., and D.L. Laskin. 1994. Regulation of hepatic endothelial cell and macrophage proliferation and nitric oxide production by GM-CSF, G-CSF and IL-1 $\beta$ following acute endotoxemia. J. Leukocyte Biol. 55:507-513.

48. Spitzer, J.A. 1994. Cytokine stimulation of nitric oxide formation and differential regulation of hepatocytes and nonparenchymal cells of endotoxemic rats. Hepatology. 19:217-228.

49. Oshita, M., Y. Takei, S. Kawano, T. Hijioka, E. Masuda, M. Goto, Y. Nishimura, H. Nagai, S. Iio, S. Tsuji, et al. 1994. Endogenous nitric oxide attenuates ethanol-induced perturbation of hepatic circulation in the isolated perfused rat liver. Hepatology. 20:961-965.

50. Nakata, K., G.F. Leong, and R.W. Brauer. 1960. Direct measurement of blood pressures in minute vessels of the liver. Am. J. Physiol. 199:1181-1188.

51. Shibayama, Y., and K. Nakata. 1985. Localization of increased hepatic vascular resistance in liver cirrhosis. Hepatology. 5:643-648.

52. McCuskey, R.S. 1965. A dynamic and static study of hepatic arterioles and hepatic sphincters. Am. J. Anat. 119:455-478.

53. Zhang, J.X., W. Pegoli, and M.G. Clemens. 1994. Endothelin-1 induces direct constriction of hepatic sinusoids. Am. J. Physiol. 266:G624-G632.

54. McCuskey, R.S. 1994. The hepatic microvascular system. In The Liver, Biology and Pathobiology. I.M. Arias, editor. Raven Press, Ltd., New York. 1089-1106.

55. Pinzani, M., P. Failli, C. Ruocco, A. Casini, S. Milani, E. Baldi, A. Giotti, and P. Gentilini. 1992. Fat-storing cells as liver-specific pericytes. Spatia dynamics of agonist-stimulated intracellular calcium transients. J. Clin. Invest. 90:642-646.

56. Rockey, D.C., C. Housset, and S.L. Friedman. 1993. Activation-dependent contractility of rat hepatic lipocytes in culture and in vivo. J. Clin. Invest. 92:1795-1804.

57. Housset, C., D.C. Rockey, and D.M. Bissell. 1993. Endothelin receptors in rat liver: lipocytes as a contractile target for endothelin-1. Proc. Natl. Acad. Sci. USA. 90:9266-9270. 